\title{
EFFECT OF THE ATMOSPHERE ON THE PERFORMANCES OF AVIATION TURBINE ENGINES
}

\author{
Włodzimierz BALICKI ${ }^{*}$, Paweł GŁOWACKI ${ }^{*}$, Stefan SZCZECINSKI ${ }^{*}$, Ryszard CHACHURSKI ${ }^{* *}$, Jerzy SZCZECIŃSK ${ }^{* * *}$
}

\author{
*Aviation Institute, Propulsion Department, Al. Krakowska 110/114, 02-256 Warszawa, Poland \\ "Military University of Technology, Faculty of Mechatronics and Aviation, ul. Sylwestra Kaliskiego 2, 00-908 Warszawa, Poland \\ ${ }^{* *}$ GE Poland, Al. Krakowska 110/114, 02-256 Warszawa, Poland
}

Balicki@ILot.edu.pl, Pawel.Glowacki@ILot.edu.pl, Ryszard.Chachurski@WAT.edu.pl; Jerzy.Szczecinski@GE.com

\begin{abstract}
The paper presents how the parameters defining the state of the atmosphere: pressure, temperature, humidity, are affecting performance of the aircraft turbine engines and their durability. Also negative impact of dust pollution level is considered as an important source of engine deterioration. Article highlights limitation of the aircraft takeoff weight (TOW) and requirements for length of the runways depending on weather condition changes. These problems stem from the growing "demand" of gas turbine engines for an air. The highest thrust engines have air mass flow more than $1000 \mathrm{~kg} / \mathrm{s}$. Engine inlet ice formation is presented as a result of weather conditions and inlet duct design features.
\end{abstract}

Key words: Power Plant, Aircraft Engine, Turbine Engine, Inlet Icing, Standard Atmosphere

\section{INTRODUCTION}

Aviation, like any other form of transport is dependent on the atmosphere conditions (weather). Hence the need to analyze the impact of the environment on the lift force, drag, and a thrust of the aircraft engines. The values of these parameters are proportional to the density of the air.

While in practice, the effect of an altitude on the engine thrust is considered, influence of the temperature and humidity is often overlooked. Higher values of these two parameters are decreasing the lift force and engine thrust. Such conditions are limiting safe takeoff of heavy loaded aircraft (including aerostats). Higher humidity increases the likelihood of inlets icing and can cause engine shutdown during flight.

The phenomenon, which is hard to observe is a gradual loss of thrust due to the erosive effects of dust on the aerodynamic profiles of the blades and vanes, and its deposition in cavities of engine ducts where locally speed is reduced or direction of airflow is changed. The source of dust are mainly contaminated runways, industry, and occasionally volcanic eruptions or dust storms.

Considerations were done for engines performances on takeoff ranges. The values of the engine parameters (rotor speed and exhaust gas temperature) are limited by the control system.

\section{CLIMATE AND THE AIRPORT ALTITUDE INFLUENCE ON THE ENGINE TAKEOFF PERFORMANCES}

Assuming that a jet engine has fuel mass flow supplied to the combustor much smaller than the air mass flow, and assuming the full expansion in the exhaust nozzle, thrust of the engine can be described by the relation:
$K=\dot{m} \cdot\left(c_{5}-V_{H}\right)=Q_{\text {pow }} \cdot \rho \cdot\left(c_{5}-V_{H}\right)$

where: $\dot{m}$ - air mass flow, $c_{5}$ - exhaust gases velocity, $V_{H}-$ airspeed, $Q_{\text {pow }}$ - volumetric airflow, $\rho$ - air density

Atmospheric air parameters (pressure, temperature and density) are changing with altitude above sea level (ASL), which of course affects the performance of aircraft engines. Lowermost airports are located at altitudes close to sea level, while some of them are in the Andes and the Himalayas at altitudes exceeding $3000 \mathrm{~m}$, and even reaching $4500 \mathrm{~m}$

For engine performances comparison, generally is used model of the International Standard Atmosphere (ISA), in which it is assumed that at sea level $(H=0)$ the air pressure is $101325 \mathrm{~Pa}$, temperature of an air is equal to $288.15 \mathrm{~K}$, and the air density is $1.225 \mathrm{~kg} / \mathrm{m}^{3}$. This model does not consider humidity changes. Calculation of engine performances assumes that the air is completely "dry". Besides the standard atmosphere, due to the considerable diversity of climatic conditions in the world, additional models of the atmosphere - cold, hot and tropical (Trop) also has been developed, for which the adopted pressure changes are the same as for the standard atmosphere model but different changes in temperature, and hence the change in air density. The described models depending on the airport height above sea-level are shown on Figs. 1, 2 and 3.

The need to take into account temperature changes depending not only on the altitude at which the airport is situated but depends also on latitude. Airports located on similar altitudes for the polar circle have OAT $-50^{\circ} \mathrm{C}$, while in the airports located in Africa and Asia OAT exceeds $+50^{\circ} \mathrm{C}$.

In the case of relative humidity we have to consider that in $=$ tropical regions often exceeds $90 \%$ at the temperatures approx. $+30 \ldots+35^{\circ} \mathrm{C}$, while in the same time at the airports located on the same altitude, but in Central Europe conditions may prevail 
in where the temperature will correspond to standard conditions and the relative humidity does not exceed $10 \%$.

Calculations carried out for the model of turbofan engine at standard conditions with a thrust approx. $100 \mathrm{kN}$ are showing that when the engine is running and the pressure corresponds to the standard (Fig. 4) it has thrust $12 \%$ higher at the temperature less by $+35^{\circ} \mathrm{C}$ than the reference, and $22 \%$ lower if the ambient temperature rises by the same amount in relation to the reference temperature.

In case, if that engine will operate from airport situated on altitude close to $4500 \mathrm{~m}$, the thrust will be about $38 \%$ less than this can be achieved at the airport, located at sea level.

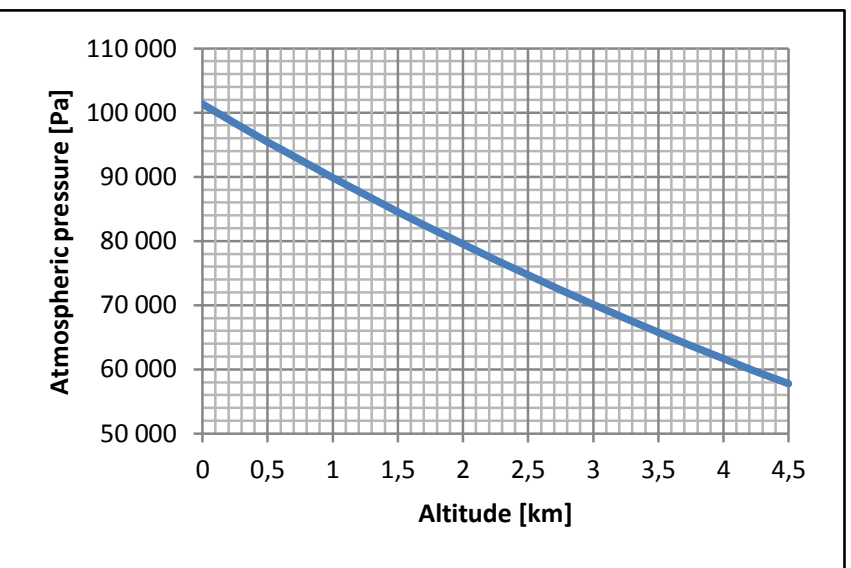

Fig.1. Changes of the atmospheric pressure with the altitude

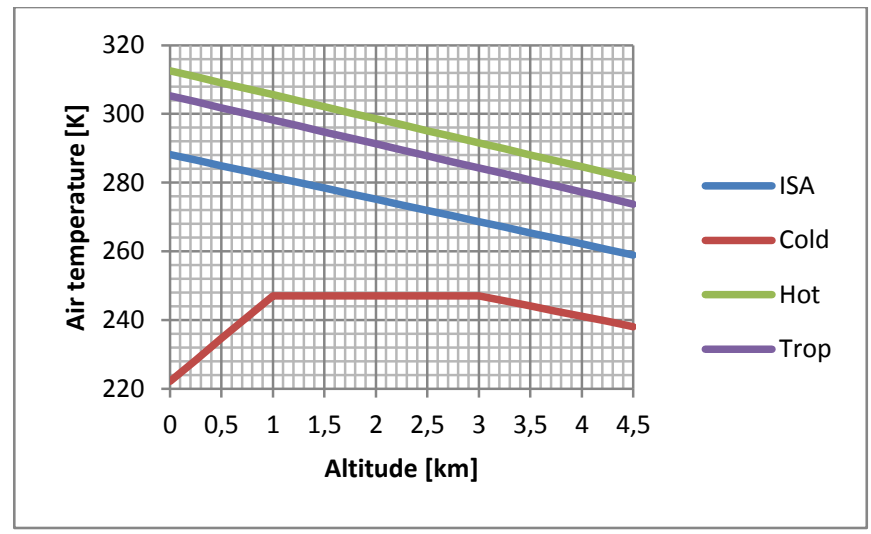

Fig. 2. Changes of the air temperature with the altitude

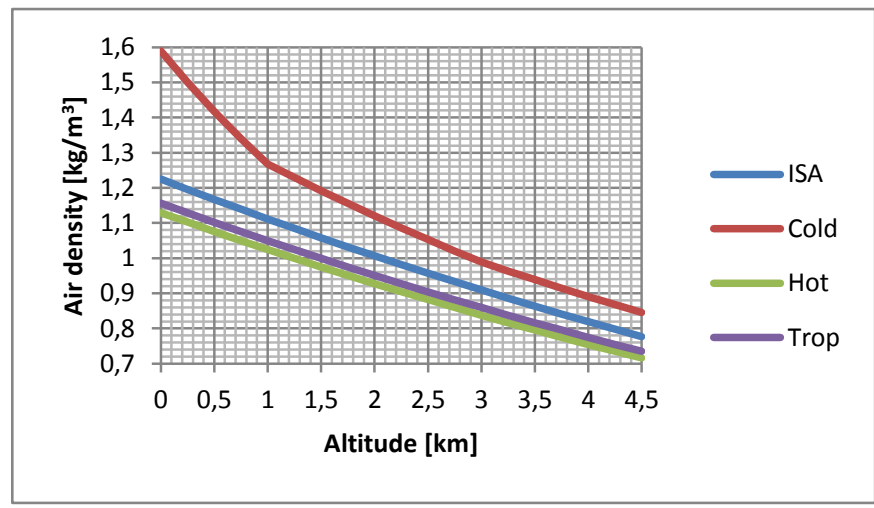

Fig. 3. Changes of the air density with the altitude

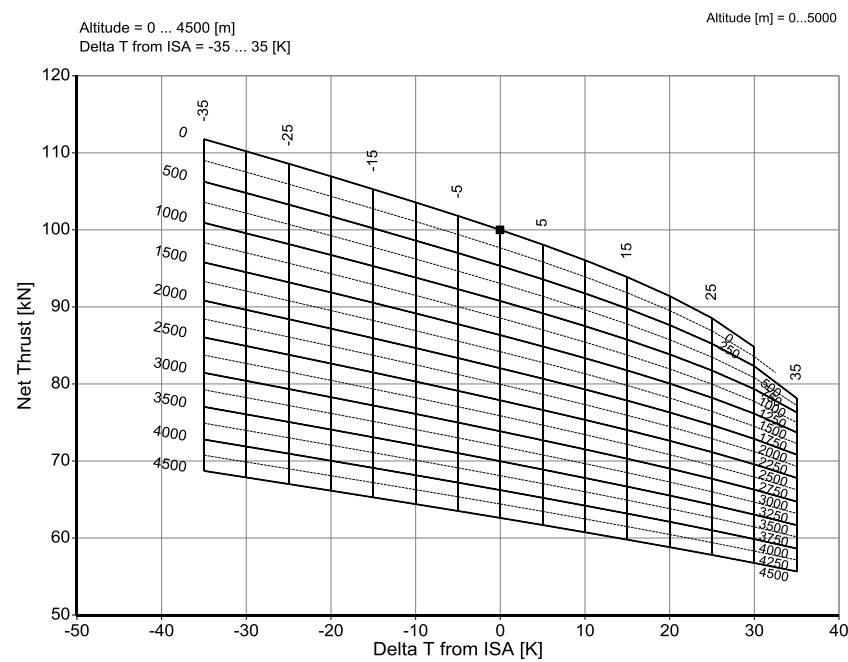

Fig. 4. Changes of the engine thrust with the altitude and the temperatures from $-35^{\circ} \mathrm{C}$ to $+35^{\circ} \mathrm{C}$ (dark dot - the conditions corresponding to ISA, generated by GasTurb 12 program)

\section{INFLUENCE OF ATMOSPHERIC CONDITIONS $\left(\mathrm{T}_{H}, \mathbf{p}_{H}\right)$ AND AIRPORT ALTITUDE ON AIRCRAFT PERFORMANCES}

Formulas for lift force $P_{z}$ and for drag force $P_{x}$ of the aircraft are including multiplier - atmospheric air density $\rho H$ (2).

$$
P_{z}=\frac{1}{2} \cdot c_{z} \cdot V_{H}^{2} \cdot S \cdot \rho_{H}, P_{x}=\frac{1}{2} \cdot c_{x} \cdot V_{H}^{2} \cdot S \cdot \rho_{H}
$$

where: $c_{\mathrm{z}}$ - lift force coefficient, $\mathrm{c}_{\mathrm{x}}$ - drag force coefficient, $\mathrm{V}_{\mathrm{H}}$ - flight speed, $\mathrm{S}$ - wing lifting surface.

This causes that changes of the lift force and the drag force with changes in temperature and altitude of the airport are proportional to changes in the density of the air. Since the lift force coefficient is much greater than the coefficient of drag force the decrease in air density decreases drag force, but much more lift force is reduced. During take-off pilot can increase lift force by flap extension, but this increases the drag force. As a result, the necessary value of the lift force can be achieved by increase of $\mathrm{V} 2$ speed. This causes building of the longer runways, and in addition as already mentioned before, under such conditions the crew has less thrust from the engines. For example, while Chopin Airport runways have length of $2800 \mathrm{~m}$ and $3620 \mathrm{~m}$ runway of Daocheng Airport at an altitude of $4411 \mathrm{~m}$ has a length of $4200 \mathrm{~m}$ and located slightly below Bamda Qamdo Airport has a runway with astonishing length of $5500 \mathrm{~m}$.

\section{INFLUENCE OF AIR HUMIDITY ON ENGINE AND AIRCRAFT PERFORMANCES}

Changes of the engine thrust as a function of the relative humidity significantly are affected by OAT. In the ISA temperature increase in relative humidity from 0 to $100 \%$ causes a slight decrease of thrust $(1 \ldots 2 \%)$, but in tropical conditions ISA $+30^{\circ} \mathrm{C}$ in the same humidity changes as above causes decrease of thrust approx. $16 \%$ of which $4 \%$ solely from the change of relative humidity of the air (Fig. 5). 


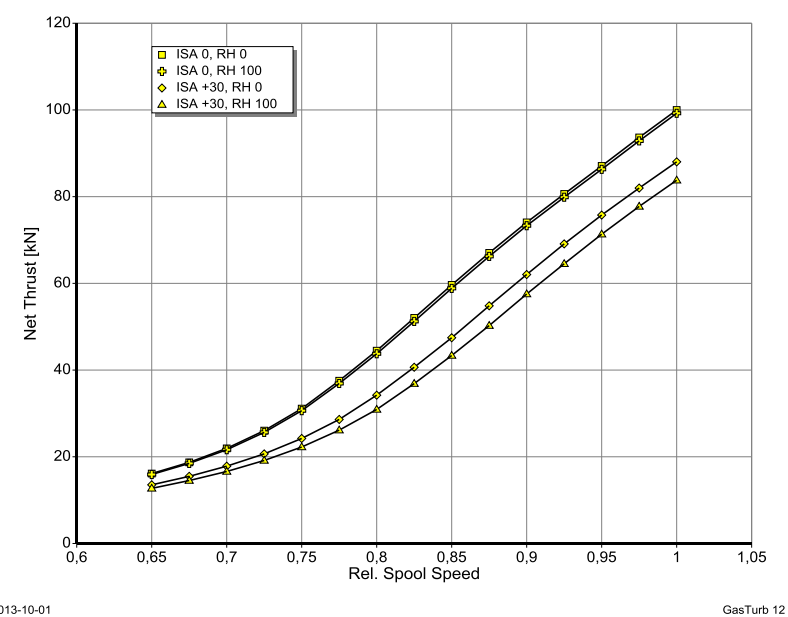

Fig. 5. Changes of the engine thrust with the relative speed N2 for a different relative humidity and OAT (generated by GasTurb 12 program)

Steam in the air reduces the mass flow, which leads to a reduction in engine thrust or power. We should also remember that is like anaerobic filling of the air, which in the case of large quantities, e.g. due to evaporation of water along gas path of the compressor or evaporation it in large quantities directly in the combustion chamber, can lead to the flame out, which means uncommanded engine shutdown.

High humidity can also cause icing of the engine, which can occur in temperatures between $+10^{\circ} \mathrm{C} \ldots+15^{\circ} \mathrm{C}$ and corresponding relative humidity. Icing formations depend on engine design, as well as inlets position on the airframe and their structure. For example, during flight aircraft powered by turbofan engines with high by pass ratio under conditions of super cooled water droplets, may have ice formation on: the inlet leading edge, inlet duct, spinner and on the fan blades as well as on OGV's, low pressure compressor IGV's and first stage blades. Three shaft engines can face in such flight icing conditions on IGV's and IPC's first stage blades.

Ice formation on the inlet duct surface sand directly on the compressor inlet, changes the geometry and cross section diameter of the duct and as a consequence reduces airflow and the parameters of airflow before compressor inlet (Chachurski, 2009). These negative changes are decreasing compressor pressure ratio which leads to engine thrust or power reduction, often to compressor instability and as a result high vibration or even engine shutdown. Instability of the compressor is also caused by distortion of duct ribs, vanes and blades airfoils.

Reduced airflow, distortion of the velocity, pressure and temperature circumferential distribution as well as inlet and IGV's airfoils distortion causes also negative circumferential distribution and increase of the temperature before turbine.

Small amount of water injection before compressor inlet increases engine thrust by improving efficiency of its thermodynamic cycle and the growth of mass flow (Water injected before the compressor gradually evaporates, absorbs heat from the air reducing the temperature, increasing its density, which at a constant volumetric flow increases the air mass flow $(\dot{m}=\rho \cdot Q)$ due to increase in air density and in addition weight of the injected water. In contrast, steam is only anaerobic filler decreasing amount of the air entering the engine.). Opposite, water inform of liquid or as snow, ice or slush, which gets to the inlet and then passes through the duct leading to serious disruption of engine performances (Recommended Practices for the Assessment of the Effect of Atmosphere Water Ingestion on the Performance and Opera-bility of Gas Turbine Engines, 1995). In subsequent stages of the compressor the air temperature rises due to the pressure increase. Water sucked into the compressor duct is gradually evaporating. Normally water in liquid form is rejected due to the centrifugal force by the rotor blades on the surface of compressor duct and then flows towards the combustion chamber. This water can get into the bleed valves. If all of the water does not evaporate in the compressor or will not be removed by bleed valves can enter the combustor and may lead to the engine shutdown. Large amount of water vapor worsen preparation and combustion of the air -fuel mixture and moreover, water can rapidly (quasi detonation) vaporize becoming anaerobic filler of the air stream in the combustion chamber causing flame out.

If there is airframe icing, then decreases the lift force, drag force increases, and further increases the weight of the aircraft. For example, if the lifting surfaces of the A380-800 have an ice layer with a thickness of $1 \mathrm{~mm}$, than the aircraft weight would be increased by about $780 \mathrm{~kg}$.

Different anti icing systems are used depends on aircraft type to protect the engine and an airframe. It should be remembered that when anti ice system works causes a decrease in engine thrust, especially when system is heated by the air from the compressor.

\section{INFLUENCE OF OTHER EXPLOITATION CONDITIONS ON ENGINE PERFORMANCES}

Engines are important for flight safety but hail, sand, dust and salt flowing with the air through engine ducts are forming deposits on flow pass surfaces and airfoils or even causing mechanical damages to the engine. Engine performances are deteriorating hence aircraft characteristics are different than calculated.

Engines are damaged most often during taxiing, take-off and landing by objects ejected from the ground by landing gear or thrust reverser. Also inlet-vortex (or ground-vortex) phenomenon causes FOD. In order to prevent engine against FOD a number of organizational and design measures are taken by the industry. Firstly, risk awareness training for ground staff. Secondly, development of a suitable methodologies for takeoff and landing. Design features include installation of particle separators on helicopter inlets or special shapes of the engines inlet ducts. Suction of dust, even particles with a small diameter is leading to wear of engine parts and as a consequence efficiency reduction, which in the turn induces an increase of EGT (Exhaust Gas Temperature) because of higher fuel consumption in order to keep required performance level of the engine.

Takeoff EGT depends on the OAT (Outside Air Temperature) and control system settings. EGT increases with increasing of OAT (Fig. 6a) while the maximum engine thrust is constant. When OAT exceeds certain value EGT is limited by the engine control system, which means further increase of the ambient temperature decreases available engine thrust (Fig. 6b). The maximum temperature value (corner point) below which engine thrust is not decreasing varies between $30^{\circ} \mathrm{C} \ldots .35^{\circ} \mathrm{C}$.

For each type of the engine manufacturer specifies the maximum permissible limit of the EGT. For example, for CFM56-3 engines the exhaust gas temperature limit is $1230 \mathrm{~K}$. 
EGT during takeoff (but also during lower ranges of engine operation) increases with the engine deterioration. Lower efficiency of the engine main modules (in particular compressor), requires more fuel delivered to the combustor in order to keep the same rotor speed (same engine thrust) to compensate lower compressor pressure ratio.

Higher EGT may indicate erosive wear of the compressor or turbine blades, increased tip clearances or distortion of airfoils by dirty deposit of oil and dust mixture (Dunn et all., 1987; Tabakoff and Hamed, 1984. At the beginning of engine operation after installation on the aircraft EGT is growing rapidly (about $12^{\circ} \mathrm{C} . .150 \mathrm{C}$ during the first 1000 cycles) compared to the test cell and then stabilizes at $8^{\circ} \mathrm{C} \mathrm{..} 10^{\circ} \mathrm{C}$ per 1000 cycles (Fig. 6c). The large EGT increase in the initial period of engine operation in relation to the values measured in the test - cell is due to the fact that there are ideal conditions during manufacturer engine tests.

As a result of engine deterioration, EGT margin becomes smaller (Fig. 6d).
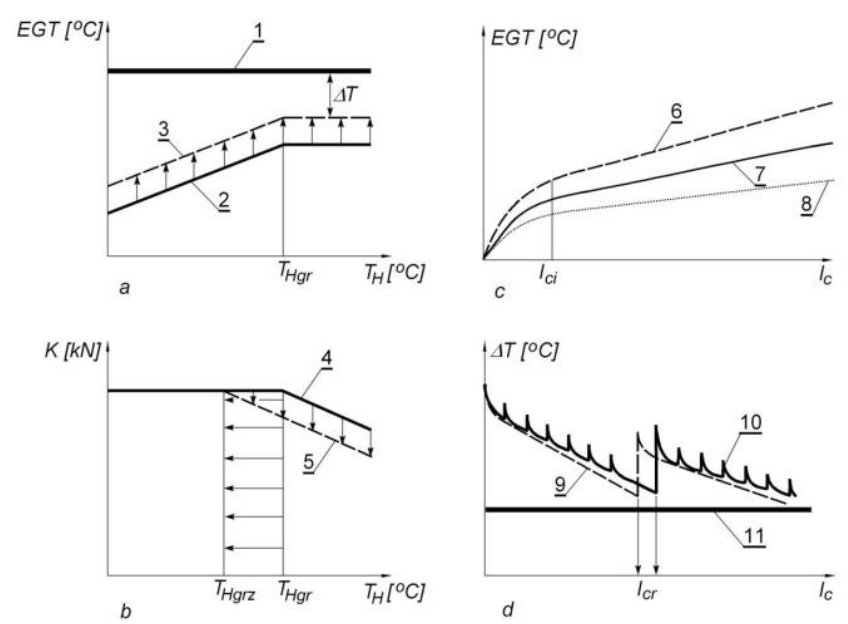

Fig. 6. OAT influence on EGT (a) and the thrust $\mathrm{K}$ (b); EGT (c) and EGT margin $\Delta \mathrm{T}(\mathrm{d})$ changes depending on the number of cycles: 1 - EGT limit, 2 - New engine takeoff EGT, 3 - Takeoff EGT of the deteriorated engine , 4 - available thrust of a new engine, 5 - available thrust of a deteriorated engine, 6 - EGT of the "dirty" engine, 7 - mean EGT, 8 - EGT of the "clean" engine, $9-\Delta T$ not washed engine, $10-\Delta T$ of the washed engine, $11-\Delta T$ limit, $T_{H G R}$ - OAT limit for a new engine, $T_{H g r z}-O A T$ limit for deteriorated engine, $l_{c}$ - the number of engine cycles, $l_{c i}$ - the number of engine cycles when $\Delta T$ is decreasing per 1000 cycles, $l_{c r}-$ the number of engine cycles for repair.

In order to improve the efficiency of the engine by removing dirty deposit accumulated on the blades and vanes operators are performing washing and cleaning of the engine at regular intervals recommended by the engine manufacturer, but operators have the right to adjust these intervals to suit their needs resulting from the specific engine operating conditions (dust, humidity, hot or cold temperatures, short or long flight routes, etc.). These processes are also used in case of an excessive reduction of $\Delta T$, and after FOD or bird strikes, etc.

\section{FINAL COMMENTS}

Any unexpected to pilot thrust decrease during takeoff has adverse impact on safety. In extreme cases - the accumulation of factors that reduce thrust: heat, high humidity and low pressure - even threatened disaster. Under the influence of extremely adverse weather conditions the engine may shutdown automatically as a result of the compressor instability. Engine thrust can be unexpectedly reduced (or even the engine can shutdown) by the automatic control system to protect power plant from being damaged due to excessive increase in exhaust gas temperature.

With this in mind the technical staff and flight crew should possess the ability to predict the impact of current or forecasted weather conditions on the aircraft and helicopters and their power plant performances.

\section{REFERENCES}

1. Balicki W., Chachurski R., Głowacki P., Godzimirski J., Kawalec K., Kozakiewicz A., Pagowski Z., Rowiński A., Szczeciński J., Szczeciński S. (2010), Aviation Turbine Engines. Design Exploitation - Diagnostic. Part I, Scientific Publications of the Institute of Aviation, Warsaw (in Polish).

2. Balicki W., Chachurski R., Głowacki P., Godzimirski J., Kawalec K., Kozakiewicz A., Pąowski Z., Rowiński A., Szczeciński J., Szczeciński S. (2012), Aviation Turbine Engines. Design Exploitation - Diagnostic. Part II, Scientific Publications of the Institute of Aviation, Warsaw (in Polish).

3. Balicki W., Chachurski R., Głowacki P., Kozakiewicz A., Kawalec K., Pągowski Z., Szczeciński S. (2009), Inlets - Threat from the inlet vortex and methods of avoid it, Transactions of the Institute of Aviation, $\mathrm{nr}$ 4/2009 (199), 17-24, (in Polish).

4. Chachurski R. (2009), Inlet icing of turbine engines, Transactions of the Institute of Aviation, no 4/2009 (199), 31-49, (in Polish).

5. Dunn M. G., Padova C., Moller J. E., Adams R. M. (1987), Performance Deterioration of a Turbofan and Turbojet Engine Upon Exposure to a Dust Environment, Journal of Engineering of Gas Turbine and Power, Vol. 109/341, 336-343.

6. Global Climatic Data for Developing Military Products (1997), Department of Defense, USA.

7. Recommended Practices for the Assessment of the Effect of Atmosphere Water Ingestion on the Performance and Operability of Gas Turbine Engines (1995) AGARD-AR-332, NATO Science and Technology Organization, (modif. 14 Feb. 2014)

8. Tabakoff W., Hamed A. (1984), Installed Engine Performance in Dust-Laden Atmosphere, AIAA Aircraft Design Systems and Operations Meeting, San Diego, California,

9. Taylor C.F. (1992), The Internal Combustion Engine in Theory and Practice, The MIT Press, Vol. 1, Second Edition,

10. The Effect of Humidity on Engine Power at Altitude, Report no 426, NACA Central, Cranfield, U.K. 